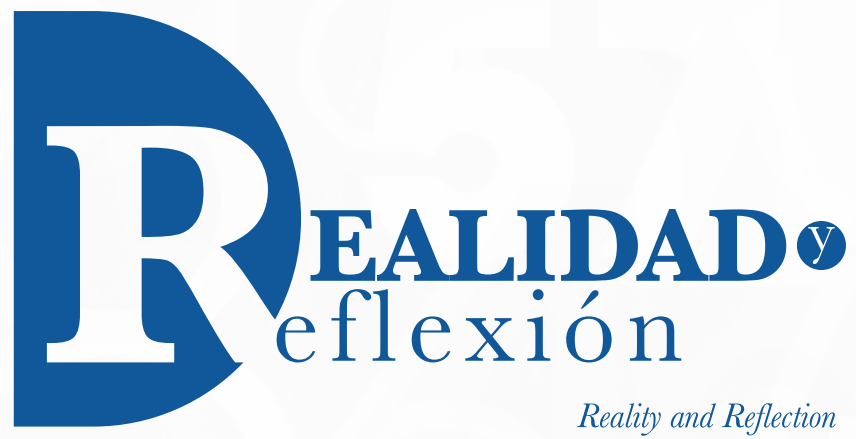

ISSN 1992-6510

e-ISSN 2520-9299

Año 21, N 53, San Salvador, El Salvador, Centroamérica. Revista Semestral Enero-Junio 2021

YEAR 21, $N^{\circ}$ 53, SAN SALVADOR, EL SALVADOR, CENTRAL AMERICA. SEMESTRAL JOURNAL JANUARY-JUNE 2021

\title{
O desenvolvimento do pensamento algébrico de estudantes em início de escolarização
}

\section{El desarrollo del pensamiento algebraico en estudiantes al inicio de la escolarización}

\section{The development of algebraic thinking of students at the beginning of schooling}

Kátia Gabriela Moreira Universidade São Francisco (USF) ktiagabriela@hotmail.com

Adair Mendes Nacarato Universidade São Francisco (USF) ada.nacarato@gmail.com

Recebido: 29 de junho de 2020 Aceito: 11 de setembro de 2020 DOI: $10.5377 /$ ryr.v53i53.10895

(c) (i) (2) 


\section{RESUMO}

O presente artigo centra-se no movimento de produção de significados relacionados ao Pensamento Algébrico. A investigação foi realizada ao longo do ano letivo de 2017 em uma sala de aula de um primeiro ano do Ensino Fundamental — que atende crianças de 6 anos de idade - composta por 26 alunos de uma escola municipal no interior do estado de São Paulo, Brasil. Para a documentação da pesquisa, as aulas da professora-pesquisadora foram videogravadas e serviram de apoio para a escrita de narrativas pedagógicas. Nestas, realiza-se a análise microgenética orientada para os indícios que permitem a interpretação dos episódios observados, possibilitando a aproximação com os processos de desenvolvimento do Pensamento Algébrico dos alunos. A análise aponta indícios de que os estudantes do primeiro ano do Ensino Fundamental, engajados numa cultura social de sala de aula de Matemática, pautada na problematização, na qual são protagonistas do próprio processo de aprendizagem, são capazes de generalizar o padrão da sequência por meio da linguagem materna.

Palavras-chave: desenvolvimento do Pensamento Algébrico, anos iniciais, pesquisa da própria prática.

\section{RESUMEN}

El presente artículo se centra en el movimiento de producir de significados relacionados al pensamiento algebraico. La investigación fue realizada a lo largo del año lectivo 2017 en una clase de primer año de Educación Básica ${ }^{\mathrm{i}}$ que comprende niños de seis años de edad - compuesta por 26 alumnos de una escuela municipal del interior del estado de São Paulo, Brasil.Para la documentación de la investigación, las clases de la profesora-investigadora fueron grabadas en video sirviendo de apoyo para la escritura de narrativas pedagógicas. En estas narrativas se realiza el análisis microgenética dirigido hacia los indicios que permiten la interpretación de los episodios observados, permitiendo la aproximación a los procesos referentes al desarrollo del pensamiento algebraico de los alumnos. El análisis muestra que los alumnos del primer año de educación básica comprometidos en una cultura social de salón de clase de Matemática enmarcada en la problematización, y en la cual son protagonistas de su propio proceso de aprendizaje, son capaces de generalizar el patrón de la secuencia por medio del lenguaje materno.

Palabras clave: Desarrollo del pensamiento algebraico, años iniciales, investigación de la práctica propia.

\section{ABSTRACT}

This article focuses on the motion of production of meanings related to algebraic thinking. The investigation was carried out throughout the academic year of 2017 in a classroom of a first year of elementary school - which serves children of six years of age - composed of 26 students from a municipal school in the interior of the state of São Paulo, Brazil. The teacher-researcher's classes were videotaped as a means of research documentation and served as support for the writing of pedagogical narratives. A microgenetic analysis of the narratives is 
carried out oriented to the indications that allow the interpretation of the episodes observed, enabling the approximation of the processes related to the development of students' algebraic thinking. The analysis of the pedagogical narrative points to evidence that the students of the first year of elementary school, engaged in a social culture of the mathematics classroom based on problematization and in which they are protagonists of their own learning process, are able to generalize the pattern sequence through their maternal language.

Keywords: Development of algebraic thinking, early years, research of own teaching practice. 


\section{Introdução}

O presente artigo é um recorte de uma pesquisa mais ampla, no âmbito de doutorado (desenvolvida pela primeira autora e orientada pela segunda), que analisa narrativamente a prática de uma professora-pesquisadora que buscou desenvolver o Pensamento Algébrico (PA) de alunos do primeiro ano do Ensino Fundamental, que tinham 6 anos. No recorte aqui apresentado, centramos nosso olhar para a produção de significados relacionados ao PA a partir de uma tarefa envolvendo a percepção e generalização do padrão de uma sequência recursiva.

A pesquisa sobre o Pensamento Algébrico nos anos iniciais é recente no Brasil. As discussões oficiais diante desse campo surgiram em 2012, a partir da publicação realizada pelo Ministério da Educação (2012) de um documento no qual a área de Matemática aparece organizada em cinco eixos: Números e Operações; Pensamento Algébrico; Espaço e Forma; Grandezas e Medidas; e Tratamento da Informação. A partir de então, os documentos curriculares passaram a contemplar o eixo do PA desde o início da escolarização dos alunos — até então, o ensino da álgebra era inserido no currículo a partir do $7^{\circ}$ ano, atendendo alunos de 12 a 13 anos de idade. A Base Nacional Comum Curricular (BNCC), cuja versão foi aprovada em 2017, é o documento curricular de âmbito nacional mais recente publicado no Brasil. Após algumas modificações ao longo de sua elaboração, o eixo Pensamento Algébrico — presente no documento de 2012 passou a ser denominado como Álgebra.

Ainda que, no Brasil, tais discussões estejam em fase embrionária, pesquisas de países que já discutem há mais tempo as questões referentes ao trabalho com o PA dos alunos desde o início da escolarização revelam resultados favoráveis. Tais resultados se destacam nos estudos de autores como: Blanton e Kaput (2005); Carraher et al. (2008); Vale (2006); Mason (2007); Cyrino e Oliveira (2011); Mestre (2014); e Radford (2008, 2012, 2013, 2014).

O artigo está organizado em quatro seções. Listamo-las a seguir: "O desenvolvimento do Pensamento Algébrico no início da escolarização sob a perspectiva histórico-cultural"; "Metodologia"; "Narrativa pedagógica: Padrões com tampas"; "Análise da narrativa da professora-pesquisadora".

\section{O desenvolvimento do Pensamento Algébrico no início da escolarização sob a perspectiva histórico-cultural}

Nas discussões dos pesquisadores, embora com algumas variações em suas concepções, é consensual a potencialidade e necessidade da introdução do trabalho com o PA já nos primeiros anos do Ensino Fundamental. Prioriza-se a construção dos conceitos algébricos enquanto um processo que se desdobra de modo amplo e envolve as propriedades dos números e das operações, as igualdades numéricas, a mudança, os padrões e as relações entre quantidades. Embora não sejam introduzidas, necessariamente, 
as notações algébricas convencionais, essas práticas permitem a utilização da linguagem materna e de outras representações para expressar ideias algébricas.

Se, por um lado, as pesquisas apontam a potencialidade e necessidade do desenvolvimento do Pensamento Algébrico desde o início da escolarização, por outro, ainda há uma grande lacuna em investigações que sinalizem as implicações pedagógicas e os caminhos possíveis para esse trabalho em sala de aula.

No caso brasileiro, há divergências terminológicas nos documentos nacionais, que variam entre os termos Pensamento Algébrico (Ministério da Educação, 2012) e Álgebra (Ministério da Educação, 2017), e nos textos teóricos, nos quais também encontramos a denominação raciocínio algébrico. A partir disso, percebemos a necessidade de aprofundamento teórico em busca de uma distinção entre eles. No entanto, na própria literatura, existem divergências entre os termos - o que torna a distinção entre eles uma ação ainda mais difícil, visto que não há um consenso entres os autores. Contudo, vários estudos têm elementos importantes que caracterizam o PA.

Squalli (2000) aponta a necessidade de distinção entre Álgebra e PA, entendendo a Álgebra como um "tipo de atividade matemática" e considerando "o pensamento algébrico como um conjunto de habilidades intelectuais que intervém nessas atividades” (p. 277). Segundo o autor, o pensamento matemático é constituído por três componentes: (1) a construção e interpretação de modelos algébricos; (2) a manipulação de expressões algébricas a partir de regras pré-estabelecidas; (3) a elaboração e aplicação de estruturas e procedimentos algébricos. Já o PA é composto por habilidades que possibilitam pensar analiticamente sobre os componentes da Álgebra. A partir do PA, os alunos generalizam e abstraem relações, regras e estruturas, e manipulam a linguagem algébrica. Assim, enquanto a Álgebra pode ser concebida como um tipo particular da atividade matemática, o PA é um conjunto de habilidades intelectuais necessárias à Álgebra. A Álgebra e o PA são apresentados pelo autor como conceitos complementares e indissociáveis (Squalli, 2000).

De modo geral, os autores evidenciam que a introdução da Álgebra desde o início da escolarização precisa ser compreendida como o desenvolvimento de um modo de pensar que antecede o uso da linguagem algébrica. Assim, amparadas pelos estudos teóricos, assumimos o uso da expressão Pensamento Algébrico, visto que entendemos a relação dialética entre o pensamento e a linguagem, o que é coerente com a perspectiva histórico-cultural, na qual a prática pedagógica e investigativa do presente estudo se ampara. Cyrino e Oliveira (2011), a partir de uma revisão de literatura, entendem "o termo Pensamento Algébrico como um modo de descrever significados atribuídos aos objetos da álgebra, às relações existentes entre eles, à modelação, e à resolução de problemas no contexto da generalização destes objetos" (p. 103). Outros autores do campo da educação matemática discutem o PA partindo da perspectiva histórico-cultural, a exemplo de Radford (2012, 2013, 2014) e Mason (2007). 
Radford (2012), pautando-se nas relações entre pensamento e linguagem discutidas por Vigotski, considera que o desenvolvimento do pensamento requer que se considere

os vários componentes que nele intervêm (por exemplo, percepção, gestos, fala, artefatos e símbolos). Também é imperativo investigar a maneira pela qual cada um desses componentes significa e se transforma à medida que novos complexos de significado surgem e evoluem. (p. 121)

O desenvolvimento da percepção é da mesma natureza que o do gesto ou da atividade simbólica, e eles se constroem de maneira articulada. O pensamento pode ser considerado "uma prática social materializada no corpo (como ações cinestésicas, gestos, percepção, visualização), no uso de signos (exemplo, símbolos matemáticos, gráficos, palavras escritas e faladas) e artefatos de tipos diferentes (regras, calculadoras, etc.)” (Radford, 2012, p. 120). Para o autor, portanto, o pensamento é uma unidade sistêmica que inclui múltiplas linguagens e formas culturais e historicamente constituídas, e, por meio de mediações semióticas, pode ser desenvolvido em sala de aula. $\mathrm{O}$ desafio consiste em investigar como esses diferentes componentes (percepção, gestos, fala, artefatos e símbolos) são transformados nos processos de significação e como eles se inter-relacionam, organizam-se e reorganizam-se no desenvolvimento do PA desde os anos iniciais. Não se trata de um processo inato, "é preciso considerar as condições contextuais que produzem novas formas de pensamento possível” (Radford, 2012, p. 121).

Apoiando-se também nas relações entre pensamento e linguagem, Mason (2007) aponta a generalização como "o coração da Matemática”, revelando, assim, a importância da generalização na aprendizagem da Matemática. O autor destaca a relação entre a palavra e o PA, visto que a palavra é fundamental para a generalização. O pesquisador defende, ainda, que os alunos, já no início da escolarização, são capazes de generalizar a partir de casos particulares, uma vez que essa ação se apresenta como uma ferramenta que o ser humano usa para dar sentido ao mundo que o cerca. No entanto, há que se considerar a necessidade de os alunos estarem envolvidos em contextos que possibilitem a construção de significados para a generalização, ou seja, circunstâncias em que expressem suas ideias, fortalecendo e ampliando essa capacidade de generalização.

As crianças, ao integrarem o processo de generalização, por meio da palavra e de seu significado, estão imersas - o tempo todo - em contextos de busca pelo particular no geral e pelo geral no particular. Para Mason (2007), os seres humanos produzem sentidos para suas experiências e usam suas capacidades para coletar, classificar e até mesmo rejeitar sensações, sejam elas físicas ou imaginadas. Com isso, a imaginação é significada no desenvolvimento humano, o que permitirá que as imagens, os diagramas ou os símbolos atuem como mediadores da aprendizagem e desenvolvimento dos alunos. No entanto, essa capacidade de imaginação, precisa ser estimulada por meio dos diferentes contextos, sobretudo o da sala de aula, possibilitando a expressão de regularidades e o estabelecimento de relações (Mason, 2007). 
A generalização se apresenta como um aspecto fundamental do ensino, principalmente nos anos iniciais. Contudo, um dos maiores desafios do ensino é a construção e ampliação desses conceitos matemáticos de maneira significativa, de modo que os alunos sejam capazes de - partindo dessa construção - comunicar, representar e estabelecer conexões matemáticas. Uma forma de desenvolver a capacidade de generalização é sensibilizar as crianças para a distinção entre "olhar para e olhar através”, conjugando-se esta última como a capacidade de ver a generalização a partir do particular.

Adotamos neste trabalho a definição de Blanton e Kaput (2005). Eles caracterizam o PA como um "processo em que os alunos generalizam ideias matemáticas a partir de um conjunto de exemplos particulares, estabelecem essa generalização através do discurso da argumentação, e expressam-na gradualmente de uma forma simbólica apropriada a sua idade” (p. 413)

A generalização pode ser manifestada de diversas formas. Inicialmente, as crianças podem expressar as generalizações que observam no mundo com palavras e, gradualmente, usar formas mais simbólicas. No entanto, a ideia do trabalho com o desenvolvimento do Pensamento Algébrico desde os primeiros anos da escolarização não focaliza a constituição de uma linguagem formal com a manipulação de símbolos, mas sim as formas de pensamento na produção de significados vivida pelo aluno. Cyrino e Oliveira (2011) ressaltam que, "dependendo do nível de experiência dos alunos, estas generalizações podem ser expressas por palavras ou por símbolos, baseados na observação de padrões ou em relações funcionais" (p. 102). Foi nessa perspectiva que a presente pesquisa desenvolveu-se.

Carraher et al. (2008) apontam que as “(. .) generalizações precisam surgir em atividades associadas a situações ricas e vivenciadas (. . )" (p. 3, tradução livre ${ }^{1}$ ). Ou seja, os alunos precisam ser envolvidos em contextos problemáticos, de modo que utilizem as representações e a linguagem natural. Nesse contexto, o professor, a partir de sua intencionalidade pedagógica, assume um importante papel na criação de um ambiente de problematização que pode contribuir para o desenvolvimento do PA dos alunos. Tal ambiente é entendido como o movimento possibilitado pela resolução de problemas, pela circulação de significados no trabalho com os alunos, o que implica interações - alunos entre si e estudantes com a professora - diálogo, troca de ideias, compartilhamento e intervenção da professora, evidenciando a necessidade de produzir questionamentos das atividades dos alunos, estimulando-os como investigadores e construtores de seu próprio conhecimento (Bagne, 2012).

No ambiente de problematização, a prática pedagógica do professor precisar ter a intencionalidade de promover a aprendizagem e o desenvolvimento dos alunos. Ele é responsável pelo planejamento, pela escolha de tarefas que priorizem o diálogo e a troca de ideias, pela construção de uma cultura de sala de aula pautada na elaboração conceitual e pela disponibilização de ferramentas matemáticas que possam ser tomadas como dispositivos de aprendizagem. Também cabe a ele garantir a equidade e a

1 “(...) generalizations need to arise in activities associated with rich experimental situations (...)”. 
acessibilidade nas aulas de Matemática, de maneira que, partindo daquilo que os alunos já conhecem, as tarefas provoquem avanços na aprendizagem e no desenvolvimento (Hiebert et al., 1997).

Nosso trabalho se ancora na perspectiva histórico-cultural, com os estudos de Lev Vygotski e seus seguidores. Nessa perspectiva, o desenvolvimento humano é um acontecimento social, em que a apropriação dos bens culturais é proveniente das relações com as pessoas. Portanto, a educação é entendida como o processo de humanização dos sujeitos, e essa "humanização" é possibilitada pela apropriação dos meios culturais historicamente construídos pela humanidade. A escola, por sua vez, é a instituição responsável pelo fornecimento de conhecimentos que possibilitem o desenvolvimento das máximas possibilidades, ou seja, a escola tem como meta a apropriação dos conhecimentos científicos por parte dos alunos. Ao mesmo tempo, constitui-se como instituição responsável por promover a relação entre os conhecimentos científicos e os cotidianos/espontâneos - aqueles que os alunos levam para o contexto escolar. Os envolvidos nesse processo (alunos e professor) formam-se por meio das relações sociais, mediados pelos signos e pelos instrumentos. Tais considerações produzem implicações pedagógicas importantes, como o reconhecimento da importância da palavra (significado, sentido e significações), a intervenção do outro e a intencionalidade pedagógica do professor.

Outro conceito importante da teoria vygotskiana é a Zona de Desenvolvimento Proximal ou Zona de Desenvolvimento Próximo, a ZDP. Esse conceito é caracterizado por Vygotski (2009) como a distância entre o nível de desenvolvimento real — aquilo que o aluno já consegue fazer de modo independentee o nivel de desenvolvimento proximal - aquilo que o aluno consegue fazer a partir da intervenção do outro. $\mathrm{O}$ autor defende que, para uma compreensão adequada do desenvolvimento, há que se considerar, para além do que a criança consegue realizar sozinha — o desenvolvimento real —, o nível de seu desenvolvimento potencial/proximal, ou seja, aquilo que ela consegue realizar com a ajuda do outro. Essa "zona de desenvolvimento" seria o caminho que o sujeito percorre para desenvolver as funções que estão em processo de consolidação; consolidadas, tornam-se o desenvolvimento real.

De acordo com Oliveira (1997), "é na zona de desenvolvimento proximal que a interferência de outros indivíduos é mais transformadora” (p. 61). Desse modo, a intervenção do professor e de crianças mais avançadas em determinados assuntos pode contribuir para a promoção de desenvolvimento do outro. Concordamos com Freitas (1997) quando afirma que "a ação compartilhada, permeando o espaço pedagógico, humaniza o processo educacional” (p. 308). Contudo, há que se tomar cuidado com o sentido atribuído ao termo intervenção, visto que a perspectiva histórico-cultural não sugere uma postura diretiva e autoritária - característica do ensino tradicional. Vygotski (2009) se preocupa com a importância do meio cultural e as relações sociais no desenvolvimento humano.

A partir desses aportes teóricos, consideramos, para o trabalho em sala de aula, tarefas que permitam trocas entre os alunos. A “ajuda” do outro (professora ou colega) na realização das tarefas é fundamental — aqui, aquilo que eu consigo fazer com a ajuda do outro garante a atuação na ZDP. 
Na próxima seção, apresentamos a metodologia da pesquisa desenvolvida. Nela, indicamos o contexto da pesquisa, a abordagem escolhida e a forma como foi feita a produção dos dados.

\section{Metodologia}

A investigação foi realizada ao longo do ano letivo de 2017 em uma sala de aula de um 1o ano do Ensino Fundamental — que atende crianças de 6 anos de idade - composta por 26 alunos, de uma escola municipal no interior do estado de São Paulo. Para a documentação da pesquisa, as aulas da professora-pesquisadora foram videogravadas, posteriormente, transcritas, e serviram de apoio para a escrita de narrativas pedagógicas. Tais narrativas partem dos pressupostos da perspectiva históricocultural e são embasadas pelos estudos de Góes (2000). Com isso, foi realizada a análise microgenética orientada para os indícios que permitem a interpretação dos episódios observados, possibilitando a aproximação do desenvolvimento do PA dos alunos.

Conforme definem Prado et al. (2011), as narrativas pedagógicas são "textos predominantemente narrativos e autobiográficos, escritos para compartilhar lições aprendidas a partir da experiência, da reflexão sobre a experiência, da observação da prática dos pares, da discussão coletiva, da leitura, do estudo e da pesquisa” (p. 143). Os autores destacam alguns gêneros discursivos que podem ser considerados como narrativa pedagógica: os memoriais de formação, as cartas pedagógicas, as crônicas do cotidiano, os depoimentos, os diários e os relatos de experiência e de pesquisa. Essas possibilidades textuais se apresentam como dispositivos para que "os educadores documentem o que fazem, o que pensam, o que pensam sobre o que fazem, assim como suas inquietações, dificuldades, conquistas, sua produção intelectual" (Prado et al., 2011, p. 143). Os pesquisadores apontam ainda que todo relato pode ser considerado como narrativa pedagógica, desde que possibilite a reflexão. Logo, a narrativa pedagógica se apresenta como um dispositivo de dizeres e escritas dos educadores da e na escola. Esses textos revelam não somente os dilemas desses sujeitos, mas também desejos e expectativas, além de mostrarem possibilidades de reflexão e transformação na/da prática pedagógica.

Partindo de uma perspectiva que valoriza as relações dialógicas de sala de aula, as trocas e as negociações de significações enquanto apropriação de conhecimentos, há que se pensar em tarefas que privilegiam tal ambiente de investigação. Entendemos que o que caracteriza a qualidade da tarefa é a coerência com seu conteúdo bem como as relações que podem ser estabelecidas a partir dela. Este último elemento será determinado a partir dos movimentos de intervenção pela prática do professor e dos alunos. Por isso, adotamos o termo tarefa para as situações propostas em sala de aula, no sentido de que ela, ao entrar em contato com a cultura social estabelecida, pode vir a ser ou não uma atividade mobilizadora de significados, mas isso só pode ser definido à medida que os alunos se sentem mobilizados e, efetivamente, colocam-se em atividade. O conceito de atividade é defendido por Leontiev (1983) enquanto a atividade principal da criança - aquela que é promotora de desenvolvimento e aprendizagem, e envolve os interesses e necessidades das crianças —, tal conceito é ampliado pelos 
estudos de Davidov (1988), que defende a atividade a partir de um ensino "desenvolvimental", em que os conhecimentos científicos são tomados como base do processo educacional.

Ao longo do ano de 2017, os alunos foram envolvidos no desenvolvimento de uma sequência de tarefas com o foco no pensamento funcional e no relacional ${ }^{2}$, ambos aconteceram simultaneamente, sem, necessariamente, seguir uma ordem ou padrão preestabelecido. Isso também ocorreu com o desenvolvimento das tarefas, que não foram propostas de maneira cronológica entre as semanas, visto que nem sempre foi possível conciliar a pesquisa com a docência e que esta precisa atender às demandas de conteúdo e de avaliações externas exigidas pela rede municipal de ensino.

O tempo de cada tarefa era relativo, sempre era sensível ao que os alunos expressavam. Havia dias em que os diálogos rendiam, sobretudo os da socialização, que sempre tomavam mais tempo; em contrapartida, havia dias em que os alunos estavam mais cansados, o que fazia com que a professorapesquisadora parasse as discussões e, quando necessário, retomasse-as em outros momentos.

Para este estudo, a análise se centrará na narrativa pedagógica Tarefa das tampas, produzida pela professora-pesquisadora. Ela foi desenvolvida com os alunos na segunda quinzena do mês de novembro/2017, ou seja, no final do ano letivo, quando a turma já havia vivenciado uma série de tarefas que envolviam contextos de sequências com padrões repetitivos e recursivos. A tarefa foi proposta aos estudantes organizados em duplas/trios. A escolha dos grupos foi realizada pela docente, que, de maneira intencional, buscou possibilitar troca entre as duplas - juntou aquele que já tinha o domínio ou se aproximava do código escrito, e assim poderia fazer a leitura do enunciado, com aquele que estava em processo de apropriação; uniu aquele que manifestava argumentos orais e/ou escritos com facilidade com aquele que tinha certa dificuldade em se expressar oralmente.

Além disso, em alguns casos, foi necessário considerar aspectos do relacionamento interpessoal entre as crianças, visto que algumas duplas, embora fossem entendidas como um encontro favorável para trocas e interações, afetivamente não conseguiam estabelecer uma parceria e entravam em conflitos que prejudicavam o desenvolvimento da tarefa.

Para a realização das tarefas, amparada pelos estudos de Van de Walle (2009), a professorapesquisadora seguiu o formato de aula em três fases: antes, durante e depois. Cada fase de trabalho tinha planejamento e objetivos específicos. A fase antes era destinada à verificação; buscavase averiguar se os alunos entenderam a proposta da tarefa. Ela envolvia o esclarecimento das expectativas da tarefa antes que os alunos começassem a trabalhar - incluindo a organização do material, das duplas/trios, e o levantamento dos conhecimentos espontâneos/cotidianos. Sendo

2 A maioria das tarefas dessa sequência faz parte do acervo do Grupo Colaborativo em Matemática (Grucomat), publicadas em Nacarato e Custódio (2018). 
assim, após distribuir a tarefa para as crianças, a professora realizava a leitura do enunciado, uma vez que a maioria não era alfabetizada. Além disso, buscava construir a problematização para a interpretação da proposta. Com o passar do desenvolvimento da sequência de tarefas, à medida que as crianças começaram a se alfabetizar, a professora passou a disponibilizar um tempo para que tentassem realizar a leitura do enunciado sozinhas, depois, ela realizava a leitura com eles, seguida das problematizações.

$\mathrm{Na}$ fase durante, os alunos tinham a oportunidade de resolver os problemas com os pares. Nesse momento, a professora assumia uma postura de observação e avaliação; quando necessário, realizava problematizações intervindo no processo dos alunos. Como não conseguia passar por todas as duplas, a docente adequava as intervenções, procurava mesclar as problematizações nas duplas em cada tarefa, deixando algumas para o momento da socialização.

Por fim, a terceira fase, depois, era destinada à socialização e discussão das estratégias utilizadas para a resolução da tarefa. Era uma nova oportunidade para que a professora entrasse em contato com as concepções dos alunos e para que se apropriassem das ideias trabalhadas. Nesse momento, ocorria a sistematização dos conceitos apresentados pela tarefa. Para essa fase, a professora buscava socializar as respostas das crianças e encaminhava as problematizações para as percepções de regularidade e generalizações das noções matemáticas; ou seja, era o momento de sistematização destas últimas.

A seguir, apresentamos a narrativa pedagógica em que são relatados os episódios de sala de aula. Tais episódios estão organizados por turnos, estes aparecem com a inicial $T$, seguida da numeração, de acordo com sequência em que aparecem na narrativa. Para preservar a identidade das crianças, optamos por utilizar nomes fictícios, as falas da professora-pesquisadora, por sua vez, aparecem com a inicial $P$ (professora). A narrativa, por ser um gênero escrito pela professora-pesquisadora, está na primeira pessoa do singular.

\section{Narrativa pedagógica: Padrões com tampas}

Na segunda quinzena do mês de novembro de 2017, os alunos foram envolvidos na realização da tarefa Padrões com tampas, com o objetivo de que entrassem no movimento de percepção de regularidade e desenvolvessem estratégias de generalização. A tarefa foi realizada em dois dias consecutivos. Primeiramente, disponibilizei aos alunos as tampas (reutilizadas de garrafas plásticas de refrigerante) para que as duplas as explorassem livremente - esse momento é fundamental para o início de uma tarefa que envolve o uso de materiais manipulativos, visto que conhecer os objetos, desenvolver curiosidades e experimentar possibilidades faz parte do planejamento e desenvolvimento da proposta. Após o momento da exploração, os alunos receberam uma folha com o enunciado da tarefa (Quadro 1). 


\section{Quadro n.* 1}

Padrões com tampas

\section{PADRÕES COMTAMPAS}

\section{TAREFA 1}

OBSERVE A SEQUENCIA ABAIXO:

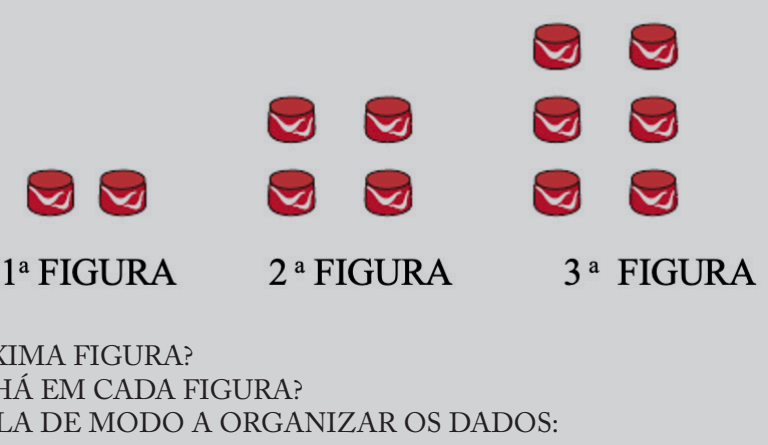

\begin{tabular}{|c|c|}
\hline NÚMERO DA FIGURA & NÚMERO DE TAMPAS \\
\hline 1 & \\
\hline 2 & \\
\hline 3 & \\
\hline 4 & \\
\hline$\ldots$ & $\ldots$ \\
\hline
\end{tabular}

4. QUANTAS TAMPAS TERÁ A 9a FIGURA?

5. E A 20 ? ?

Dei um tempo para que as crianças buscassem suas estratégias para ler o enunciado. Elas ainda estavam no processo de apropriação da leitura e da escrita. Durante esse momento, a aluna Jade me questionou: "Professora, mas nós não temos dados." - fazendo referência ao termo "dados" do terceiro item do enunciado e relacionando-o ao objeto utilizado em jogos e brincadeiras para a contagem, o hexaedro com as faces numeradas de 1 a 6 . Tal questionamento me fez refletir sobre a importância desse primeiro momento da análise realizada pelas crianças e sobre a relevância de estar atenta às significações dos alunos diante dos enunciados, visto que os estudantes podem atribuir diferentes sentidos ao texto, sendo necessária a negociação de significações para o desenvolvimento da proposta. É importante que as crianças tenham tempo suficiente para pensar, elaborar suas hipóteses e falar sobre estas, uma vez que nem sempre atribuem o mesmo significado que a professora ao enunciado da tarefa.

Bakhtin (1988) explica que os sentidos de uma palavra não existem em si mesmos, como algo dado. Os sentidos são elaborados nas enunciações, e estas, por sua vez, fazem parte de um diálogo social. 
O enunciado "é o território comum do locutor e do interlocutor" (Bakhtin, 1988, p. 113) — todo enunciado refere-se a, pelo menos, dois sujeitos: procede de alguém e dirige-se a outro alguém. Logo, os sentidos carregam marcas das condições sociais nos quais são produzidos, por isso são, em parte, nossos e, em parte, do outro, em uma interação entre os locutores. $\mathrm{O}$ sentido é produzido e significado sempre na interação de vozes! Para apontar o sentido expresso por "dados" no enunciado, utilizei o contexto de uma tarefa realizada anteriormente pela turma, em que os estudantes também foram envolvidos na construção de uma tabela com os "dados" da sequência, buscando o que Radford (2008) chama de "movimento de iconicidade", caracterizado pela disposição de um repertório de experiências importantes que permitem retomadas e (re)significações por parte dos alunos.

Depois do momento inicial da tarefa, fiz a leitura coletiva com os alunos, novamente negociando as significações das crianças e até discutindo algumas questões levantadas por eles. Em seguida, Maíra me procurou e afirmou:

Episódio 1 - Descoberta de Maíra

T01 Maíra: Professora, eu descobri a do 9. 9+9, dá 18!

T02 P: O que você pensou para descobrir?

T03 Maíra: Eu pensei na do 5.

T04 P: E o que a gente fez na do 5?

T05 Maíra: A gente pensou quanto é $5+5$.

T06 P: E se eu pensar na 20?

T07 Maíra: 40!

T08 P: E se eu pensar na 21?

T09 Maíra: [pensativa] eu vou lá pensar...

T10 P: Olha, 20 é 40! E 21?

T11 Maíra: 41!

O episódio aponta indícios da síntese da análise realizada pela Maíra diante da regularidade da sequência: "Prô, eu descobri a do 9. 9+9, dá 18" (T01). A aluna utilizou a adição do número do termo $(\mathrm{n}+\mathrm{n})$ para determinar a quantidade de tampas no termo 9. Mas como ela teve essa percepção? “Ora, professora, a partir do que fizemos, coletivamente, no termo 5, agora eu consigo realizar, sozinha, no termo 10". Ou seja, o que antes era realizado com a ajuda do outro passa a ser feito de maneira autônoma. Nesse sentido, penso que as ações a partir da tarefa estão, de fato, atuando na ZDP das crianças (Vygotski, 2009).

$\mathrm{Na}$ sequência, desafiei a aluna a pensar sobre outros termos (T06, T08). Será que sua "regra" era válida para todos os termos da sequência? A aluna não apresentou dificuldade para determinar a quantidade de tampas da figura 20 (T07), evidenciando sua apropriação da estratégia de generalização (n + n). Contudo, quando questionei sobre o termo 21, esbarramos em um novo desafio: como realizar a 
adição 21 + 21 ? Sugeri dar um passo para trás, quando pensávamos na adição 20 + 20 (T10). Então, Maíra afirmou que o resultado dessa adição seria 41 (T11). Apesar de incoerente, penso que sua fala tem uma lógica válida; afinal, eu não havia adicionado uma unidade ao número da soma anterior? Todavia, era necessário considerar que era uma unidade em cada parcela da adição, o que resultaria no total de 42 tampas. Vale destacar que a adição com números de maior magnitude ainda estava em processo de construção com as crianças, visto não fazer parte do currículo adotado na rede de ensino; os alunos elaboravam estratégias de cálculo mental, e Maíra tentava encontrar a soma dessa adição; no entanto, naquele momento, ela não conseguiu resolver a adição, mas chegou a uma lei de formação, a partir de um discurso de argumentação (Blanton \& Kaput, 2005).

Para o fechamento da tarefa, propus a socialização das estratégias utilizadas pelas crianças. Para algumas - que estavam engajadas na análise e na busca por uma generalização —, este se tratava de um momento de síntese; mas, para aquelas crianças que ainda estavam apropriando-se da tarefa ou mesmo da regularidade da sequência, era uma nova oportunidade de (re)significação e, consequentemente, de aproximação à proposta da tarefa. Logo, as crianças que ainda não estavam mobilizadas pela busca por regularidades poderiam fazê-la com minha ajuda e a de colegas mais experientes.

Episódio 2 - Aumentando de 2 em 2

T01 P: Que tipo de sequência é essa?

T02 Jade: Vai pulando de 2 em 2.

T03 Pedro: Aumenta de 2 em 2.

T04 P: Vai pulando ou aumentando de $2 \mathrm{em} 2$ ?

T05 Alunos: Aumentando.

T06 Antônio: De 3 em 3...

T07 P: Como assim, Antônio?

T08 Antônio: Ali vai aumentando de $3 \mathrm{em} 3$.

T09 P: Vem aqui me explicar!

T10 Antônio: [vai até a lousa e aponta para as duas colunas da figura 3]

T11 P: Ah, eu entendi... O que o Antônio pensou, gente?

T12 Gabriela: No número da figura...

T13 Pedro: Também tá pulando de $2 \mathrm{em}$ 2, porque aqui [vai até a lousa e aponta para os espaços entre as figuras] pulou o 3, aqui o 5, aqui o 7...

T14 P: A Maíra observou uma coisa... Fala Maíra!

T15 Maíra: É uma sequência de números pares...

T16 Antônio: O 2 épar!

T17 P: Será que a Maíra está correta?

T18 Antônio: Está, porque o 2 é par, $04 \ldots$

T19 Jade: 06 épar, o 8 é par, o 10 é par...

T20 P: Agora eu quero saber como eu sei quantas tampas têm na figura 9. 
T21 Lia: 9!

T22 P: 9?

T23 Lia: Não... 8!

T24 P: Você acha que tem um a menos, igual àquela tarefa ${ }^{3}$ ? [aponta para o cartaz na parede ${ }^{4}$ ]

T25 Lia: 11!

T26 Jonathas: 20 !

T27 Aluno: 18!

No início do episódio, percebo que as crianças negociavam significações para o que ocorre na sequência: "Será que ela está aumentando ou pulando de 2 em 2? Teria diferença entre esses termos?" (T02, T03, T05). Perdi a oportunidade de questioná-los. Contudo, ao refletir acerca dessa questão, recordome das tarefas em que utilizamos a reta numérica - a análise dos episódios também me possibilita o movimento de iconicidade (Radford, 2008). Lá realizávamos "pulos” entre os números; entretanto, a direção do "pulo" (direita ou esquerda) determinava se ele "aumentava" ou "diminuía”. Considerando esse contexto, teria sim diferença no uso dos termos!

A regularidade da sequência pode ser estabelecida, numa abordagem aritmética, de "2 em 2" ou de “3 em 3"? Esse era o levantamento das crianças, e eu estava mobilizada a descobrir quais eram suas significações. Diante da afirmação de Antônio (T06), solicitei uma explicação para sua hipótese ("3 em 3"). A partir de sua explicação, em que apontou para as "partes" da figura, entendi que, centrando sua análise na Figura 3, sua fala fazia referência à ocorrência da repetição do número da figura na quantidade de tampas dispostas em colunas. Seria impossível minha aproximação com a significação atribuída pelo aluno se estivesse partindo de uma interpretação totalmente subjetiva, sem considerar sua significação. Os alunos têm muito "a dizer" sobre "o que dizem"; e, em contrapartida, a professora tem muito "a entender" sobre o que "entende".

E não é que existem muitas maneiras de enxergar a regularidade na sequência? Veja o movimento do Pedro (T13): ele passou a considerar os "números ímpares que a sequência pulou", que estariam nos espaços em branco entre uma figura e outra - 3,5 e 7. Precisei retomar a sequência para entender seu raciocínio e considerar a regularidade apontada pelo aluno. As crianças me ajudaram a enxergar coisas que eu não poderia enxergar sozinha. E quantas coisas me passam despercebidas por não solicitar que meus pequenos expliquem o que estão pensando?!

Percebo que minha intervenção buscava envolver a classe toda, ou um número maior de crianças, no movimento de pensar junto com aqueles que procuravam uma regularidade para a sequência. No turno

3 Uma tarefa realizada anteriormente pela turma que envolvia uma sequência recursiva com palitos.

4 Ao final de cada tarefa de padrões recursivos, fizemos um registro dos resultados (que envolvia tabela, estratégias de generalizações e lei de formação) em folha de papel pardo e fixamos na parede para futuras consultas. 
14, chamei Maíra para compartilhar sua ideia com os colegas. A princípio, pensava sobre a "descoberta" que havia compartilhado comigo anteriormente; portanto, imaginei que fosse explicar sobre a soma do número do termo para a obtenção da quantidade de tampas em cada figura. Contudo, fui surpreendida com uma nova forma de enxergar a regularidade: "É uma sequência de números pares ..." Percebo que a aluna rompeu com a abordagem aritmética inicial e foi para outro tipo de abordagem, formulando uma nova hipótese. Mas o que ela estava considerando? A soma das tampas de cada figura? Se assim o fosse, sua fala estaria correta! Porém, e se ela levasse em conta outro aspecto para sua análise? Perdi a oportunidade de questioná-la!

E como os colegas reagiram a sua afirmação? Buscaram indícios para a validação de sua hipótese: "O 2 é par?”; “... o 4”; "O 6 épar, o 8 épar”; “o 10 épar...". Logo, o grupo validou a hipótese da colega. A partir da discussão, busquei (re)orientar a análise do grupo para a quantidade de tampas na figura (T20). Percebi algumas iniciativas baseadas em "tentativas e erros" (T21, T23, T25, T26). Chamou-me a atenção quando, a princípio, a aluna Lia afirmou que havia a quantia de 9 tampas (T21) e, depois de questionada, apontou para o total de 8 tampas (T23) - aqui, entendi que ela fazia referência à tarefa anterior, na qual realizávamos a subtração $(-1)$ em cada termo. Contudo, acabei me equivocando ao "induzir" o fato à aluna contando minha percepção. $\mathrm{O}$ correto seria deixar que a aluna, por si só, constatasse sua significação para a sequência, e, em vez de questioná-la com "Você acha que tem um a menos, igual àquela tarefa?", deveria ter utilizado indagações que fossem mais abertas, como: "Como assim? Por que você falou 8?".

Buscando (re)organizar a análise das crianças para que considerassem o número da figura em busca de uma estratégia de generalização, modifiquei minha pergunta:

Episódio 3 - Resgatando ideias importantes

T01 P: Será que, se eu pensar no número da figura, me ajuda a descobrir a quantidade de tampas?

T02 Alunos: Não!

T03 P: Olha... [aponta para figura 2] o número 2, tem alguma relação com a figura?

T04 Alunos: Não.

T05 P: Será? O Antônio havia dito que tinha... O que você falou naquela hora?

T06 Antônio: Tem!!!

T07 P: Qual é a relação?

T08 Antônio: A relação é que tá se repetindo...

T09 P: O que está se repetindo? Olha, o Jonatas também identificou isso. Você se lembra quando eu perguntei do 5? Você falou que era só pegar o 5 mais isso [gesticula]

T10 Jonatas: [vai até a lousa e aponta para o número da figura e associa à quantidade]. Esse 2 é aqui, olha...

T11 P: Olha o que o Jonatas descobriu! Que esse 2 [número da figura] está se repetindo aqui [número de tampas]. Figura 2, 2! [aponta para a quantidade]; Figura 1,1! [aponta para a quantidade de tampas] Figura 3?! 
T12 Alunos: 3!

T13 P: E na figura 9?

T14 Alunos: 9...9!

T15 P: Então, pra gente descobrir quantas tampas tem em uma figura...

T16 Jade: Vai precisar do número que tem... [aponta para a sequência da lousa]

Fui chamando os alunos, que tentavam encontrar uma regularidade para a sequência (T05, T09). Contudo, só consegui envolvê-los nessa discussão porque já tinha conhecimento sobre suas produções. O "caminhar" pela sala, enquanto os estudantes realizam as tarefas, é fundamental para entrar em contato com o que eles produzem, para realizar problematizações que auxiliem os saltos qualitativos de suas significações, para atuar na ZDP (Vygotski, 2009) e para selecionar suas produções para o momento da socialização.

Percebo meu movimento de intervenção em busca de resgatar os apontamentos realizados pelos alunos durante o trabalho em dupla, selecionei aqueles que julgava que contribuiriam para discussões e negociações coletivas, visando à generalização da sequência. Um exemplo é o turno 5, em que chamei Antônio para compartilhar novamente sua percepção - destacada do episódio anterior (“de 3 em 3") - com os colegas. Nesse sentido, os alunos atuam na intervenção da aprendizagem dos pares, ainda que essa intervenção, em momentos como este, necessite de meu olhar e destaque para retomar as falas dos discentes e encorajá-los a discorrer sobre suas percepções, suas hipóteses e suas estratégias.

Ainda sobre esse trecho do episódio, percebo o quanto Antônio se apropriou da circulação de ideias da sala de aula e (re)organizou sua comunicação — "A relação é que tá se repetindo..." —, visto que, anteriormente, havia pronunciado “... aumentando de $3 \mathrm{em} \mathrm{3”,} \mathrm{apoiando-se} \mathrm{na} \mathrm{situação} \mathrm{real} \mathrm{da}$ sequência. Não há como afirmar que o aluno utilizou a expressão atribuindo o mesmo significado que eu aos conceitos envolvidos, pois ele poderia estar apenas reproduzindo minha fala. Contudo, "primeiro, a criança é guiada pela palavra do outro e, depois, ela própria utiliza as palavras para orientar o seu pensamento" (Góes \& Cruz, 2006, p. 33). Além disso, Vygotski (2009) defende que os signos exercem o papel de mediadores na elaboração conceitual ${ }^{5}$; dentre os muitos signos que podem cumprir essa função, a palavra ocupa um lugar central, porque é compreendida pelo autor como meio principal de conceitualização.

Logo, ainda que Antônio estivesse "reproduzindo" minha fala para expor suas ideias, poderia considerar que ele apontava indícios de seu processo de apropriação e, consequentemente, de elaboração conceitual. Tal apropriação, no decorrer de seu desenvolvimento, será utilizada para orientar seu pensamento, transformando e reelaborando elementos de um contexto "interpessoal" para uma

5 "O conceito é impossível sem palavras, o pensamento em conceitos é impossível fora do pensamento verbal; em todo esse processo, o momento central, que tem os fundamentos para ser considerado causa corrente do amadurecimento de conceitos, é o emprego específico da palavra, o emprego funcional do signo como meio de formação de conceitos.” (Vygotski, 2009, p. 170) 
conjuntura "intrapessoal”. Por isso, "todas as funções no desenvolvimento da criança aparecem duas vezes: primeiro no nível social, e, depois, no nível individual; primeiro, entre as pessoas (interpsicológica), e, depois, no interior da criança (intrapsicológica)" (Vygotski, 2007, p. 57).

Além disso, o gesto, enquanto uma das múltiplas expressões da linguagem, desempenha um papel significativo na comunicação das ideias, das hipóteses e da análise das sequências. Tal linguagem gestual foi revelada tanto por mim - para exemplificar o dobro do número para as crianças (T11) - quanto pelos alunos, como no caso do Jonatas, que se dirigiu até a lousa para apontar os termos da sequência e, assim, explicar sua ideia para os colegas (T10). Vygotski (2007) define o gesto como a primeira forma de representação do significado. Se, por um lado, a linguagem oral possibilita a explicação por meio de palavras, a linguagem gestual, que, às vezes, complementa-a ou mesmo a substitui, busca exemplificar essas palavras.

Além disso, Radford (2012) defende que o uso de ritmo e gestos pelo professor - também apropriados pelas crianças - abre possibilidades para que elas lancem mão de diferentes recursos em busca da generalização. Tais possibilidades podem ser apropriadas e utilizadas não só na resolução de desafios atuais, mas também nas experiências que podem ser tomadas como referências importantes (movimento de iconicidade) em outras sequências. Por meio de diferentes instrumentos semióticos (fala, gesto, sonoridade), as crianças criam suas significações. Logo, tais instrumentos aproximam as crianças da elaboração conceitual.

É importante observar que a fala de Antônio deu um novo direcionamento para a análise da sequência, visto que, a partir de sua afirmação “ $3 \mathrm{em}$ 3”, que analisamos e, mais tarde, levou para a generalização, deixamos de nos envolver numa abordagem de pensamento recursivo, proposto pela tarefa, para averiguar a dependência entre o número da figura e o total de tampas de cada termo. Há aqui uma (re) orientação de nossa análise. Incluo-me nesse processo, mas só tomo consciência desse movimento ao refletir sobre o episódio.

Apostando na discussão coletiva como um importante dispositivo de aprendizagem, questionei, novamente, a turma sobre a estratégia de generalização da sequência. Alguns alunos não se manifestaram oralmente, tanto quanto outros; por isso, sempre considero "a nova oportunidade de engajar a turma toda" no movimento.

Episódio 4 - Sistematizando a discussão

T01 P: Então, eu tenho que fazer o número [enquanto fala, registra na lousa a palavra número]. $\mathrm{O}$ número do quê?

T02 Aluno: 10!

T03 P: O 10 é o número do quê?

T04 Jade: Não, prô! Tem que ser os números! 
T05 P: Aqui, o que pensamos? [aponta para figura 2]. No número da figura! Então, eu tenho que colocar o número da figura mais ...?

T06 Jade: Mais o número!

T07 P: Que número?

T08 Jade: Tipo o 33... 33 + 33 [gesticulando com as mãos uma coluna de 33 e outra de 33]

T09 P: Então é o número da figura mais o número da figura?

T10 Jade: É, o Antônio ensinou...

T11 P: Então, criamos uma regra para essa sequência! Qual é a regra?

T12 Jade: Vai se repetindo. $1+1 ; 2+2 ; 3+3 \ldots$ [enquanto fala gesticula a organização das figuras].

Como visto, fechamos a tarefa com uma lei de formação para a sequência, elaborada por meio da intervenção e da discussão coletiva. Nesse ponto, destaco a importância da socialização das ideias dos alunos, sobretudo no trabalho com crianças no início da escolarização, como é o caso de minha turma. Elas se manifestam com mais facilidade por meio da oralidade, visto que a maioria é recémalfabetizada e domina, com maior facilidade, a linguagem oral. Além disso, a socialização permite ao professor a tomada de decisões diante das significações que os alunos apontam e lhes permite a sistematização dos conceitos possibilitados pela tarefa.

Chegamos à generalização por meio da adição dos números da figura $n+n-$ se as crianças já tivessem se apropriado do conceito de multiplicação, poderíamos pensar em 2n. Percebo que as crianças lançaram mão do uso de exemplos para comunicar a estratégia de generalização: "Tipo o 33... 33 + 33" (T08), com o gesto apontando para a repetição do número na figura. Logo, entendo que, se, por um lado, a linguagem oral assume a função de designar, nomear e explicar, por outro, a linguagem gestual exemplifica! Nesse movimento, a linguagem oral e a gestual se complementam (Pinto, 2010).

Ao retomar o diálogo nos turnos 09 e 10 - "Então é o número da figura mais o número da figura; $E$ " o Antônio ensinou..." - e refletir sobre ele, percebo que, durante a aula, sou uma figura importante para a intervenção nos processos de aprendizagem dos alunos, mas não somente... Meu olhar atento (e, por vezes, desatento) busca possibilidades de interferir na elaboração conceitual das crianças. Proponho tarefas, crio situações, encorajo participações, provoco, chamo a atenção... Tudo isso para colocar em evidência os verdadeiros protagonistas da aula: as crianças! Elas são protagonistas da aula, protagonistas da elaboração conceitual de si próprias e do coletivo da sala. O lugar do protagonismo, da construção, da troca, da participação é o lugar significativo, o lugar da pertença (Ricouer, 1989). É, o Antônio ensinou e ensina a todos nós, mas não vamos esquecer que o Antônio, ao ensinar, também aprende conosco. Nossas vozes se misturam, (trans)formam-se ao se encontrarem; retornam a nós (ainda sendo nossas vozes) (re)significadas. O desenvolvimento do PA se dá no entremeio das misturas de vozes.

Para finalizar, envolvi os alunos na construção de uma tabela, em que organizamos os dados da sequência. 
Tabela n. ${ }^{\circ} 1$

Sequência de Tampas I

\begin{tabular}{|c|c|c|}
\hline NÚMERO DA FIGURA & $\begin{array}{c}\text { LEI DO } 1^{\circ} \text { ANO } \\
\text { NÚMERO DA FIGURA + } \\
\text { NÚMERO DA FIGURA }\end{array}$ & NÚMERO DE TAMPAS \\
\hline 1 & $1+1$ & 2 \\
\hline 2 & $2+2$ & 4 \\
\hline 3 & $3+3$ & 6 \\
\hline 4 & $4+4$ & 8 \\
\hline 5 & $5+5$ & 10 \\
\hline 6 & $6+6$ & 12 \\
\hline$\ldots$ & $\ldots$ & $\ldots$ \\
\hline 12 & $12+12$ & 24 \\
\hline$\ldots$ & $\ldots$ & $\ldots$ \\
\hline 40 & $40+40$ & 80 \\
\hline$\ldots$ & $\ldots$ & $\ldots$ \\
\hline 50 & $50+50$ & 100 \\
\hline
\end{tabular}

A lei de formação número da figura + número da figura $(\mathrm{n}+\mathrm{n})$, apesar de ter surgido nas discussões da socialização, foi sistematizada por meio da construção da tabela. Aqui tivemos a oportunidade de uma nova visualização da sequência. Saímos do contexto figurativo para a circunstância da tabela, na qual há a possibilidade de uma (nova) leitura e visualização da sequência. Penso que esse processo de sair do figurativo para o numérico, e o contrário também (sair do numérico para o figurativo), possibilita a (re)significação das crianças, ampliando o entendimento e reconhecimento das regularidades, e favorecendo a generalização. Essa foi uma generalização construída pelos alunos. Outra possibilidade que me ocorreu ao ter um olhar retrospectivo para essa sequência seria a recursividade de acrescentar 2 ao resultado anterior, o que geraria outra lei de formação: $2+2 .(n-1)$. Assim, a sequência proposta era recursiva, mas a generalização produzida pelos alunos não.

Reconheço a importância do uso da tabela para o processo de generalização. Hiebert et al. (1997) apontam que

a atividade matemática requer o uso de ferramentas, e as ferramentas que usamos influenciam a maneira como pensamos sobre a atividade. Outra forma de dizer isso é afirmar que as ferramentas são um recurso e suporte essencial para a construção da compreensão matemática, e as ferramentas que os alunos usam influenciam os tipos de entendimentos que desenvolvem. (p. 10, tradução livre $\left.{ }^{6}\right)$

\footnotetext{
6 "Mathematical activity requires the use of tools, and the tools we use influence the way we think about activity. Another way to say this is that tools are an essential resource and support for building mathematical understanding, and the tools students use influence the kinds on understandings they develop".
} 
Os autores argumentam que as ferramentas matemáticas podem auxiliar as crianças a fazer coisas que não poderiam fazer sozinhas, ou seja, atuam como mediadoras na aprendizagem. Entendo a tabela enquanto uma ferramenta de mediação na análise e generalização das sequências. Contudo, o uso (significativo) dessa ferramenta se dá em uma negociação de significações com os alunos. Quando decidi incluir uma tabela no enunciado, não pretendia que esse uso "significativo" acontecesse a partir dessa tarefa, não! Entendo esse "uso" como algo a ser conquistado a partir de um processo, no decorrer das negociações, das significações, no decorrer do desenvolvimento das sequências de tarefas. No contexto de minha sala de aula, essa ainda é uma ação que precisa ser atuada na ZDP (Vygotski, 2009). Ao analisar os registros dos estudantes, percebo que atribuíram diferentes sentidos para a tabela, mas ainda não se atentaram para o registro solicitado pelo enunciado, incluindo aqueles que optaram por não realizar nenhum registro. Como exemplo desse processo, tomo a construção de Pedro:

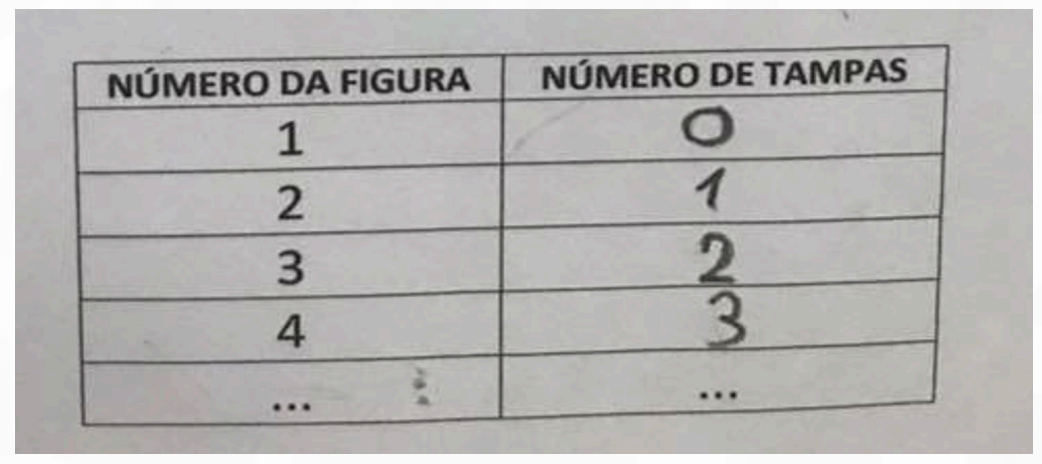

Figura n. $^{\circ}$ 1. Registro na tabela do aluno Pedro. Fonte: Acervo da pesquisadora.

"Professora, o que vou fazer com esse espaço em branco aqui? Será que tenho que escrever os números em ordem? Será que devo copiar o 'modelo'?". O aluno lançou mão do registro da sequência numérica sem se atentar para o que a coluna indicava. Outros repetiram o número que aparecia na primeira coluna. Contudo, no momento da socialização, consegui retomar questões importantes de significação para a tabela, o que eles ainda não davam conta de realizar sozinhos, faziam com minha ajuda. "E tudo bem!", entendo essa aceitação como meu processo de autoformação, visto que, num passado não tão distante, ficaria angustiada com "o que não deu certo" no desenvolvimento da proposta. Ora, estava amparada por meu planejamento, por minha intencionalidade pedagógica e (mais ainda) por minhas reflexões sobre a teoria (aliada à prática) que me permitem a compreensão e aceitação do processo (marcado por idas e vindas). Aqui, entendo que essa compreensão é importante, mas não o suficiente... É preciso um movimento "além disso"; é preciso a aceitação! É necessário reconhecer os processos de ensino e aprendizagem (em meu caso, à luz dos pressupostos da perspectiva histórico-cultural) e aceitar a prática, que envolve movimentos, tempos e "resultados" que rompem com modelos tradicionais de ensino. E está tudo bem se as crianças ainda não atribuem sentido ao uso da tabela enquanto um dispositivo importante para a organização e leitura dos dados; por meio de meu trabalho intencional, 
elas terão novas oportunidades de (re)significação — não contando com o acaso, mas sim com um planejamento intencional.

\section{Análise da narrativa da professora-pesquisadora}

Os episódios analisados na narrativa da professora-pesquisadora sinalizam para o quanto os alunos, desde o início da escolarização, são capazes de fazer generalizações por meio da linguagem materna. Isso corrobora as pesquisas tomadas como referência para este trabalho (Mason, 2007; Cyrino \& Oliveira, 2011; Radford, 2012, 2013, 2014). No entanto, há que se considerar algumas características da aula da professora-pesquisadora: há uma intencionalidade pedagógica, com objetivos explícitos para a tarefa proposta; a tarefa é cuidadosamente selecionada, inserida numa sequência mais ampla, que permitiu um movimento de iconicidade (Radford, 2008), visto que os alunos conseguiam levar para a discussão elementos conceituais já apropriados em tarefas anteriores; as tarefas são problematizadoras (Hiebert et al., 1997), possibilitando que os discursos matemáticos fossem produzidos; as interações entre os alunos e a intervenção da professora oportunizaram a circulação de ideias matemáticas e a generalização da sequência recursiva; múltiplas linguagens (oral, escrita, gestual) foram utilizadas; a docente lançou mão de uma importante ferramenta para a representação, a tabela, que favorece a percepção de regularidades na sequência e sua lei de formação. Enfim, ela criou uma cultura social de sala de aula (Hiebert et al., 1997), pautada na problematização, na qual os alunos foram protagonistas do próprio processo de aprendizagem. Nessa cultura, sua prática esta pautada nas fases da aula (Van de Walle, 2009), que, como afirmado, são estas: antes, momento que envolve o planejamento e o início da tarefa; durante, processo que engloba a realização da tarefa em que a professora-pesquisadora acompanha as discussões no grupo e seleciona argumentos dos alunos; e depois, movimento em que ocorre a discussão coletiva, em que os argumentos são validados ou não e possibilitam a elaboração conceitual. Podemos dizer que nesses episódios há indícios de um PA em desenvolvimento.

Olhando retrospectivamente para o processo de generalização dos alunos, consideramos que a professora-pesquisadora, ao oferecer as tampas para a construção da sequência, poderia ter realizado intervenções que ajudassem os alunos a generalizar a sequência recursivamente, com o acréscimo de duas unidades ao termo anterior. Os alunos argumentaram utilizando o raciocínio aditivo, visto que a multiplicação ainda não tinha sido introduzida na sala de aula. Esse teria sido um momento oportuno para tal introdução. Isso reforça a importância da pesquisa na própria prática quando o pesquisador registra os dados para análise posterior. A compreensão a posteriori dessa possibilidade proporcionou novos conhecimentos pedagógicos para a professora-pesquisadora.

Igualmente importante foi a apropriação, pela professora-pesquisadora, dos conceitos-chave da perspectiva histórico-cultural, tanto para a organização dessa cultura de sala de aula quanto para a própria análise dos episódios na narrativa produzida. Consciente de conceitos como desenvolvimento, aprendizagem, mediação, interação, papel do outro e da palavra, elaboração conceitual e linguagem, 
ela foi orquestrando a sala de aula, permitindo que os alunos expressassem seus pontos de vista, argumentassem. E eles foram até a lousa para explicar seu raciocínio. Enfim, os discentes estavam inseridos numa autêntica atividade matemática.

A narrativa da professora-pesquisadora também tem indícios de suas aprendizagens. Ao se colocar à escuta dos alunos, ela foi surpreendida em alguns momentos com as observações elaboradas pelos estudantes, que a levavam a raciocinar e validar, evidenciando a imprevisibilidade numa sala de aula quando eles podem expressar suas ideias.

Esta é uma pesquisa da própria prática da professora-pesquisadora, e sua narrativa revela a assunção da investigação como postura. Esse conceito foi desenvolvido por Cochran- Smith e Lytle (2009). Segundo as autoras, a

investigação como postura é fundamentada nos problemas e contextos da prática, em primeiro lugar, e nas formas com que os professores em exercício teorizam colaborativamente, estudam e agem sobre esses problemas para atender aos melhores interesses da aprendizagem e para oferecer melhores oportunidades de vida aos estudantes e a suas comunidades. (CochranSmith \& Lytle, 2009, p. 123, tradução livre7)

As autoras argumentam que os professores

estão profundamente engajados no trabalho de ensino e aprendizagem, sabem algo sobre esse trabalho (. . .), são capazes de gerar e criticar o conhecimento, descobrir como usar (ou não) o saber gerado por outros, melhorar a prática e intensificar as oportunidades na vida dos estudantes. (Cochran-Smith e Lytle, 2009, p. 125, tradução livre ${ }^{8}$ )

Essa é uma característica da professora-pesquisadora, que, desde sua graduação, participa ativamente de grupos de estudos e pesquisas, além de envolver-se na investigação da própria prática.

Dessa forma, identificamos sua preocupação com a organização da sala e a utilização de formas de registro (a gravação seguida da narrativa), além de notarmos como entrecruza acontecimentos na sala de aula com o movimento de pensamento dos alunos e as vozes de autores tomados como referência. Ela se revela em processo de formação, considerando a incompletude do ser humano e, assim, analisa com coerência os momentos em que poderia ter sido mais inquiridora com as crianças; ela ousou e

7 "inquiry as stance is grounded in the problems and contexts of practice in the first plane and in the ways practitioners collaboratively theorize, study, and act on those problems in the best interests of the learning and life chances of students and their communities".

8 "are deeply engaged in the work of teaching and learning know something about that work and, collectively with one another and with others (...) have the capacity to generate and critique knowledge, figure out how to use (or not use) knowledge generated by others, improve practice, and enhance students' life chances". 
analisou o que poderia ter sido de outra maneira; isso porque tinha suas aulas videogravadas, e o vídeo é uma excelente ferramenta para pesquisas em sala de aula. Mesmo tendo limites, principalmente porque o olhar é seletivo e, neste caso, a professora-pesquisadora não contava com auxiliar para ajudála na gravação, a videogravação possibilita que o pesquisador recorra a ela em vários momentos e capte as imagens e os gestos dos falantes. Por meio da análise das videogravações, é possível desvelar o cenário que se estabeleceu na sala de aula, já que se pode realizar idas e vindas e analisar o movimento de produção e (re)significação dos alunos, e, ao mesmo tempo, estudar as intervenções realizadas durante esse processo.

Ao assumir-se como professora-pesquisadora da própria prática, a docente possibilita o desenvolvimento de seus alunos. Assim, eles, com apenas 6 anos, iniciando a alfabetização, conseguiram ter argumentos matemáticos e apontar indícios de generalizações algébricas.

\section{Referências}

Bagne, J. (2010). A elaboração conceitual em matemática por alunos do $2^{\circ}$ ano do ensino fundamental: Movimento possibilitado por práticas interativas em sala de aula. (Dissertação de Mestrado). Universidade São Francisco, Itatiba.

Bakhtin, M. (1988). Marxismo e filosofia da linguagem. Problemas fundamentais do método sociológico na ciência da linguagem. São Paulo: Hucitec.

Blanton, M. L., \& Kaput, J. J. (2005) Characterizing a classroom practice that promotes algebraic reasoning. Journal for Research in Mathematics Education, 36(5), 412-443.

Carraher, D. W., Martinez, M. V., \& Schliemann, A. (2008). Early algebra and a mathematical generalization. ZDM Mathematics Education, 40, 3-22.

Cochran-Smith, M., \& Lytle, S. L. (2009). Inquiry as stance: Practitioner research for the next generation. New York: Teachers College Press.

Cyrino, M, C. C. T., \& Oliveira, H.M. (2011). Pensamento algébrico ao longo do Ensino Básico em Portugal. Bolema. Rio Claro (SP), 24(38), 97-126.

Davidov, V. V. (1988). La enseñanza escolar y su desarrollo psicológico. Moscu: Editorial Progresso.

Freitas, M. T. A. (1997). Nos textos de Bakhtin e Vygotsky: um encontro possível. In: Brait B, organizador. Bakhtin, dialogismo e construção do sentido. Campinas (SP): Editora da Unicamp. 
Góes, M.C.R.(2000, Abril).A abordagem microgenética na matriz histórico-cultural: uma perspectiva para o estudo da constituição da subjetividade. Cadernos Cedes, $X X(50)$.

Góes, M. C.R., \& Cruz, M. N. (2006). Sentido, significado e conceito: notas sobre as contribuições de Lev Vigotski. Pro-Posições, 17(2), 31-45.

Hiebert, J. et al. (1997). Making sense: Teaching and learning mathematics with understanding. Portsmouth: Heinemann.

Leontiev, A. N. (1983). Actividad, conciencia y personalidad. Havana: Editorial Pueblo y Educación.

Mason, J. (2007). Making use of children powers to produce algebraic thinking. In J. J. Kaput, D. W. Carraher \& M. L. Blanton (Eds.). Algebra in the early grades (pp. 57-94). New York: Lawrence Erlbaum Associates.

Mestre, C.M.M. V. (2014). O desenvolvimento do pensamento algébrico de alunos do 4. ${ }^{\circ}$ ano de escolaridade: uma experiência de ensino. (Tese de Doutorado). Universidade de Lisboa, Lisboa.

Ministério da Educação. (2012). Elementos conceituais e metodológicos para definição dos direitos de aprendizagem e desenvolvimento do ciclo de alfabetização $\left(1^{\circ}, 2^{\circ}\right.$ e $3^{\circ}$ anos) do Ensino Fundamental. Brasilia, DF.

Ministério da Educação. (2017). Base Nacional Comum Curricular. Educação é a base. Brasília, DF.

Nacarato, A. M., \& Custódio, I. A. (2018). O desenvolvimento do pensamento algébrico na educação básica: compartilhando propostas de sala de aula com o professor que ensina (ensinará) matemática. Brasília: Sociedade Brasileira de Educação Matemática.

Oliveira,M.K.(1997).Vygotski, aprendizado e desenvolvimento: um processo sócio-bistórico. São Paulo: Scipione.

Pinto, G. U. (2010). Imaginação e formação de conceitos escolares: examinando processos dialógicos na sala de aula.(Tese de Doutorado). Universidade Metodista de Piracicaba, Piracicaba.

Prado, G.V.T. et al. (2011, setembro/dezembro). Narrativa pedagógica e memoriais de formação: escrita dos profissionais da educação? Revista Teias, 12(26), 143-153.

Radford, L. (2008). Iconicity and contraction: A semiotic investigation of forms of algebraic generalizations of patterns in different contexts. ZDM - The International Journal on Mathematics Education, 40(1), 83-96. 
Radford, L. (2012). On the development of early algebraic thinking. PNA, 6(4), 117-133.

Radford, L. (2013). En torno a tres problemas de la generalización. In L. Rico, M C. Cañadas, J. Gutiérrez, M. Molina \& I. Segovia (Eds.). Investigación en Didáctica de la Matemática: homenaje a Encarnación Castro (pp. 3-12). Granada: Editorial Comares.

Radford, L. (2014). The progressive development of early embodied algebraic thinking. Mathematics Education Research Journal, 26, 257-277.

Ricoeur, P. (1989). Do texto à ação: ensaios de hermenêutica II. Porto: Rés.

Squalli, H. (2000) Une reconceptualisation du curriculum d'algèbre dans l'éducaction de base. Québec: Faculté des Sciences de l'Éduction, Université Laval.

Vale, I. (2006). Resolução de tarefas com padrões em contextos figurativos: exemplos de sala de aula. In I. Vale, I. Cabrita \& T. Cardoso. Matemática e Padröes no ensino básico: perspectivas e experiências curriculares de alunos e professores. Viana do Castelo: ESEVC - Projeto Padrões.

Van de Walle, J. (2009). Matemática no ensino fundamental: formação de professores e aplicação em sala de aula. Porto Alegre: Artmed.

Vygotski, L. S. (2007). A formação social da mente. São Paulo: Martins Fontes.

Vygotski, L. S. (2009). A construção do pensamento e da linguagem. São Paulo: Martins Fontes.

i La educación escolar brasileña se divide en Educação Infantil (opcional) para niños menores de cinco años, Ensino Fundamental para niños entre 6 y 15 años y que comprende dos fases: Ensino Fundamental I ( $1^{\circ}-5^{\circ}$ año) y Ensino Fundamental II ( $\left.6^{\circ}-9^{\circ}\right)$, Ensino Médio (que dura 3 años), Ensino Técnico y Ensino Superior. La investigación descrita en este trabajo se realizó con alumnos del primer año de Ensino Fundamental, término que fue traducido como Educación Básica. 